\title{
Comparing the cost effectiveness of harm reduction strategies: a case study of the Ukraine
}

\author{
Sung Wook Kim ${ }^{1 *}$, Anni-Maria Pulkki-Brannstrom ${ }^{1,2}$ and Jolene Skordis-Worrall1,
}

\begin{abstract}
Background: Harm reduction strategies commonly include needle and syringe programmes (NSP), opioid substitution therapy (OST) and interventions combining these two strategies. Despite the proven effectiveness of harm-reduction strategies in reducing human immunodeficiency virus (HIV) infection among injecting drug users (IDUs), no study has compared the cost-effectiveness of these interventions, nor the incremental cost effectiveness of combined therapy. Using data from the Global Fund, this study compares the cost-effectiveness of harm reduction strategies in Eastern Europe and Central Asia, using the Ukraine as a case study.

Methods: A Markov Monte Carlo simulation is carried out using parameters from the literature and cost data from the Global Fund. Effectiveness is presented as both QALYs and infections averted. Costs are measured in 2011 US dollars.

Results: The Markov Monte Carlo simulation estimates the cost-effectiveness ratio per infection averted as \$487.4 [95\% Cl: 488.47-486.35] in NSP and \$1145.9 [95\% Cl: 1143.39-1148.43] in OST. Combined intervention is more costly but more effective than the alternative strategies with a cost effectiveness ratio of $\$ 851.6[95 \% \mathrm{Cl}$ : 849.82-853.55].

The ICER of the combined strategy is \$1086.9/QALY [95\% Cl: 1077.76:1096.24] compared with NSP, and \$461.0/infection averted [95\% Cl: 452.98:469.04] compared with OST. These results are consistent with previous studies.

Conclusions: Despite the inherent limitations of retrospective data, this study provides evidence that harm-reduction interventions are a cost-effective way to reduce HIV prevalence. More research on into cost effectiveness in different settings, and the availability of fiscal space for government uptake of programmes, is required.
\end{abstract}

Keywords: Harm reduction, Cost effectiveness analysis, Needle and syringe programme, Opioid substitution therapy, Ukraine, Markov Monte Carlo simulation, Global Fund

\section{Background}

There are an estimated 15.9 million injecting drug users (IDUs) worldwide, $80 \%$ of whom live in developing and transitional countries [1]. The concurrent epidemics of HIV and injecting drug use have rapidly increased HIV prevalence [2], with $10 \%$ of HIV/Acquired Immunodeficiency Syndrome (AIDS) cases worldwide attributed to IDUs [3,4].

HIV prevalence in Eastern Europe and Central Asia has almost tripled since 2000 [1], to an estimated 1.4 million people in 2011 [5]. The region is also home to 3.7 million IDUs [1]. Ukraine's HIV prevalence is the highest in Europe and a 2010 study found that 50\% of IDUs in Ukraine were HIV positive [6]. The Global Fund has spent approximately $\$ 20 \mathrm{~m}$ on harm reduction in the Ukraine [7].

\footnotetext{
* Correspondence: sung.kim.11@ucl.ac.uk

'UCL Institute for Global Health, 30 Guilford Street, London WC1N 1EH, UK Full list of author information is available at the end of the article
}

Harm reduction interventions aim to reduce the harmful results of drug use. Although there is no agreed definition, a small number of interventions are commonly described in the literature as "harm reduction" including; condom provision, community based outreach, peer-led interventions, needle and syringe programmes (NSP) and opioid substitution therapy (OST) [8]. Needle and syringe programmes offer a clean needle and syringe to injecting drug users (IDUs), while opioid substitution therapy (OST) replaces heroin with a less addictive drug such as methadone or buprenorphine under medical supervision. As IDUs undergoing OST may continue drug use outside of the programme [9], combining NSP with OST may be more effective in reducing HIV transmission than a single intervention [10]. This paper will focus only on three harm reduction strategies; NSP, OST, and combined therapy (NSP and OST) based on the literature review.

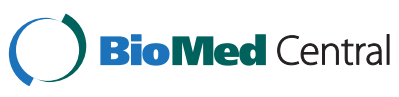


This study's purpose is to improve our understanding of the relative cost effectiveness of harm reduction strategies. A literature review on the cost-effectiveness of harm reduction describes what is known, and what is not. A cost-effectiveness analysis of harm-reduction is then conducted using data from the Global Fund for the Ukraine. The analysis compares NSP, OST and a combined intervention. To the best of our knowledge, this is the first study comparing a combined intervention with NSP or OST alone, in any setting.

\section{Literature review}

The literature on harm reduction cost-effectiveness was reviewed to summarize current evidence. Web of Science, Econlit and Pubmed were the primary databases searched. A supplementary search was conducted using Google Scholar. Reference lists of identified papers were handsearched for further appropriate papers. The search terms were: cost-effectiveness, HIV, NSP, OST, harm reduction, needle and syringe, and methadone. Only papers published in English, in peer-reviewed journals were considered.

The inclusion criteria were: 1) Studies should be about harm reduction interventions i.e. NSP, OST, or combined therapy; 2) Studies should be analyzed from a health economic perspective 3) Studies should present data on either effectiveness or cost, and 4) Studies should focus on HIV. 5) Papers not available in English or published before 1990 were excluded. The initial search identified 18 papers. After reviewing titles and abstracts, 3 were excluded. After reading the full papers, 3 further papers were excluded and 3 were added following a hand search of the reference lists. The final review includes 15 papers listed in Table 1, two of which are literature reviews themselves.

This literature review summarizes the systematic review papers [11,12] and then lists the papers published since their publication [10,13-17,19,20,22-24]. One exceptional case is the research by Van den berg et al. [21]. This study was added to bolster the evidence around the combined intervention because the majority of the papers since the systematic reviews focus on a single therapy. Only one retrieved study by Degenhardt et al. [10] focused on the effectiveness of combined intervention of NSP and OST.

The first two papers in Table 1 are reviews of harm reduction strategies by Connock et al. [12] and Jones et al. [11]. Connock et al. [12] conducted a systematic review and cost effectiveness analysis of OST. They conclude that methadone dominates buprenorphine, both of which are licensed for use as opioid substitutes. Jones et al. [11] conducted a systematic review of NSP. Jones et al. [11] conclude from their review that in terms of reducing HIV incidence and prevalence among IDUs, NSPs are cost-effective.

While the review papers aimed to explore the cost effectiveness of a single intervention, a number of studies conducted since the reviews, have attempted to compare these single interventions with an alternative. For example, Van den berg et al. [21], (cited in the review by Jones et al.) compared a combined intervention with incomplete harm reduction. They concluded that combined intervention is more cost effective than incomplete harm reduction. Van den berg et al. [13] compared full harm reduction (NSP + OST) vs incomplete harm reduction (NSP + OST). However, they assumed incomplete harm reduction always offers OST, just changing 'the dose of OST'. Therefore, patients who get incomplete harm reduction always get OST as a base case. Likewise, Degenhardt et al. [10] compared combined intervention (OST + NSP) with ART and found that combined intervention of OST and NSP and ART gained more effectiveness than either OST + NSP or ART.

All NSP studies that reported NSP as a primary intervention used 'no NSP and no intervention' as a comparator. However, studies of OST show more varied comparators; 'no OST' [15-17], combined ART intervention [10,20], and buprenorphine [12].

Of the papers listed in Table 1, ten used either QALYs gained or DALYs averted as a measure of outcome. All of the papers estimated both cost per infection averted and cost per either QALY or DALY.

In general, these studies suggest that harm reduction interventions are cost effective and particular reference is made to OST $[18,19]$ and NSP $[22,23]$. These results are derived mainly from a mathematical and epidemiological modelling $[14,15,22,23,25]$ rather than from cohort studies [21]. This review also highlights a gap in the evidence regarding the relative cost effectiveness of harm reduction strategies. It is necessary to compare which mono-therapy (OST or NSP) is more cost effective, and whether mono-therapy is more cost effective than combined intervention - whether or not ART is offered. This is not because the provision of ART is unimportant, but because the literature has moved on to evaluate the cost effectiveness of the provision of ART with harm reduction - without first considering what is the most cost effective harm reduction package. As described above, there are studies arguing for the relative cost effective of NSP [13], of OST [14] and of combined intervention [10,20,21]. However, no study that we could find compared the cost effectiveness of these three harm reduction alternatives. To fill this evidence gap, we conduct a CEA of harm reduction comparing NSP, OST, and combined intervention, using each intervention as a comparator. Exclusion of ART from harm reduction interventions appears to be feasible, considering the low ART coverage among IDUs in the Ukraine, which was $26.7 \%$ in 2004 and $24 \%$ in 2008 [26,27].

\section{Section 2: case study of the Ukraine}

The largest IDU populations in Eurasia are in the Russian Federation (1.8 million) and the Ukraine (296,000) [1]. 


\section{Table 1 Summary of systematic review result}

\begin{tabular}{|c|c|c|c|c|c|c|c|}
\hline Study & Comparator & $\begin{array}{l}\text { Intervention } \\
\text { Evaluated }\end{array}$ & $\begin{array}{l}\text { Form of economic } \\
\text { analyses }\end{array}$ & Perspective taken & Model used & Time horizon & Outcome measure \\
\hline Jones et al. [11]† & & & $\begin{array}{l}\text { Cost utility }(N=12) \\
\text { Cost benefit }(N=1)\end{array}$ & & $\begin{array}{l}\text { Behavioural models using simplified } \\
\text { Bernoulli process }(N=4) \text { simulated } \\
\text { the transmission }(N=2) \text { the theory } \\
\text { of needle circulation originally } \\
\text { developed by Kaplan and O'Keefe } \\
(\mathrm{N}=4)\end{array}$ & & $\begin{array}{l}\text { HIV incidence }(N=11) \text { HCV incidence } \\
(N=1) \mathrm{HIV} \text { and } \mathrm{HCV} \text { incidence }(\mathrm{N}=1)\end{array}$ \\
\hline $\begin{array}{l}\text { Connock et al. } \\
{[12] \dagger}\end{array}$ & & & Cost-utility $(\mathrm{N}=5)$ & $\begin{array}{l}\text { Societal perspective }(\mathrm{N}=5) \\
\text { healthcare system }(\mathrm{N}=6)\end{array}$ & $\begin{array}{l}\text { Markov }(\mathrm{N}=3) \text { Dynamic }(\mathrm{N}=3) \\
\text { Monte Carlo }(\mathrm{N}=1)\end{array}$ & & QALY $(N=6)$ \\
\hline $\begin{array}{l}\text { Belani and } \\
\text { Muennig [13] }\end{array}$ & no NSP & NSP & Cost utility & Societal & Decision model & 1 year & Infection averted \& QALYS \\
\hline $\begin{array}{l}\text { Wammes et al. } \\
{[14]}\end{array}$ & OST & $\begin{array}{l}\text { OST (coverage } 5 \% \\
\text { to } 40 \% \text { ) }\end{array}$ & $\begin{array}{l}\text { Cost effectiveness/ } \\
\text { cost analysis }\end{array}$ & Societal & Mathematical transmission model & 20 year & Infection averted \\
\hline $\begin{array}{l}\text { Guinness et al. } \\
{[15]}\end{array}$ & non intervention & OST & Cost utility & Provider & Mathematical model & 3 year & Infection averted \& DALYs \\
\hline $\begin{array}{l}\text { Tran, Mills, et al. } \\
{[16]}\end{array}$ & non OST & OST & Cost utility & Health service provider & Real cohort data & 9 month & QALYS \\
\hline $\begin{array}{l}\text { Tran, Nguyen, } \\
\text { et al. [17] }\end{array}$ & non OST & OST & cost utility & $\begin{array}{l}\text { Vietnam health care } \\
\text { system }\end{array}$ & Decision analytical model & 1 year & Infection averted \& QALYS \\
\hline $\begin{array}{l}\text { Tran, Ohinmaa, } \\
\text { et al. [18] }\end{array}$ & OST\&ART & OST & Cost utility & $\begin{array}{l}\text { Vietnam health care } \\
\text { system }\end{array}$ & Decision tree monte carlo simulation & 1 year & Infection averted \& QALYS \\
\hline $\begin{array}{l}\text { Connock et al. } \\
{[12]^{* *}}\end{array}$ & Buprenorphine & $\begin{array}{l}\text { OST (methadone } \\
\text { vs } \\
\text { buprenorphine) }\end{array}$ & Cost utility & NHS & Markov monte carlo simulation & 1 year & QALYS \\
\hline $\begin{array}{l}\text { Degenhardt } \\
\text { et al. [10] }\end{array}$ & $\begin{array}{l}\text { ART, } \\
\text { NSP\&OST\&ART }\end{array}$ & $\begin{array}{l}\text { Combined } \\
\text { (NSP\&OST) }\end{array}$ & Cost effectiveness & & Transmission model & 5 years & Infection aveted \\
\hline $\begin{array}{l}\text { Alistar, Owens, } \\
\text { and Brandeau } \\
\text { [19] }\end{array}$ & $\begin{array}{l}\text { OST\&ART ART } \\
\text { alone }\end{array}$ & OST & Cost utility & Provider & dynamic compartmental model & 20 year & Infection averted \& QALYS \\
\hline Li et al. [20] & ART, VCT & $\begin{array}{l}\text { Combined } \\
\text { (NSP\&OST) }\end{array}$ & Cost utility & & Mathematical & 30 year & Infection averted \& QALYS \\
\hline $\begin{array}{l}\text { Van den berg } \\
\text { et al.* [21] }\end{array}$ & $\begin{array}{l}\text { Methadone dose } \\
\text { or NEP use alone }\end{array}$ & $\begin{array}{l}\text { Combined (NSP\& } \\
\text { OST) }\end{array}$ & & Not stated & Cohort study & 20 years & Incidence rate ratio \\
\hline Kwon et al. [22] & no NSP & NSP & Cost utility & Health sector & Mathematical model & lifetime & Infection averted \& QALYS \\
\hline Zhang et al. [23] & no NSP & NSP & Cost utility & Societal & Mathematical model & 7 years & Infection averted \& DALYs \\
\hline
\end{tabular}

Systematic review.

${ }^{*}$ Connock et al. [12] carried out a systematic review and a cost effectiveness analysis in one paper. 
Nearly half of IDUs in the Ukraine live with HIV [1], the highest prevalence rate in Europe [6]. The Global Fund has spent approximately $\$ 20 \mathrm{~m}$ on harm reduction in the Ukraine since 2004 [7]. Considering that the Global Fund disbursed US\$ 361 million through 120 grants in 55 countries between 2002 and 2009 [28], the amount spent in the Ukraine is significant for a single country. That said, while the Global Fund provides significant international support for harm-reduction programs $[2,28]$, these investments have seldom been evaluated.

\section{Methods}

Consistent with previous research in this area [12,29], this study uses a Markov model, assuming three states of 'infected', 'uninfected (well)', and 'dropped'. The model is designed to estimate costs and outcomes in terms of QALYs and HIV infections averted over 60 months, for the three strategies. The model estimates uncertainty using probability distributions. Monte Carlo simulation was then carried out using these distributions to account for uncertainty in the results of the model.

Figure 1 illustrates one cycle of the Markov decision model in this study. 'Infected' status occurs when patients are confirmed as HIV positive while 'uninfected' occurs when patients are HIV negative. 'Dropped' means that IDUs quit any harm reduction interventions they were attending. It is assumed that there is no mortality within the 5 year harm reduction period based on the existing literature (Table 2). This assumption is consistent with the approach used by Vickerman et al. [25] (Table 2). As the objective of this study is to compare the cost effectiveness of harm reduction strategies irrespective of ART provision, ART is not offered in any intervention including 'no intervention'.

A Markov Monte Carlo simulation with 10,000 iterations was conducted. It is known that at least 440 iterations should be run to be $95 \%$ sure that the estimate of the mean of the output is accurate [36]. Consequently, it can be said that 10,000 iterations are sufficient to get a $95 \%$ confidence interval. This figure of 10,000 iterations is consistent with other research on HIV $[37,38]$ and is recommended for medical decision making generally [39]. The main outcomes are expressed as cost effectiveness ratios $(\mathrm{CE})$ and incremental cost-effectiveness ratios (ICERs).

Treeage software was used to construct the model. Sensitivity analysis was carried out to account for uncertainty in the cost data. Potential affordability of the three strategies was assessed using probability sensitivity analysis (PSA) with the GDP of the Ukraine as a threshold. Based on WHO recommendations, an intervention may be considered cost effective if the cost per QALY is less than the country's GDP per capita $[35,40]$

\section{Interventions compared}

$$
\mathrm{ICER}=\frac{c 1-c 0}{E 1-E 0}=\frac{c 1}{E 1}
$$

$\mathrm{C} 1$ is the cost of the new intervention, and E1 is the effect of the new intervention, whereas $\mathrm{C} 0$ and $\mathrm{E} 0$ are the cost and effect of the base case or comparator. Six cases were considered in this study: NSP vs OST, NSP vs NSP\&OST, NSP vs no intervention, OST vs NSP\&OST, OST vs no intervention, NSP\&OST vs no intervention. The result is shown as a form of PSA in Figures 2 and 3. The base case is a no intervention, in which IDUs do not get any harm reduction intervention.

HIV incidence was obtained from previous literature. Given the initial HIV prevalence [25], the effectiveness of each intervention was estimated. HIV incidence and infections averted, were calculated with the following formula $[16,30]$ :

$$
H I V \text { incidence }=S\left[1-p(1-\beta)^{a(1-\gamma)}+(1-p)^{n}\right]
$$

where $\mathrm{S}=$ total no of susceptible individuals (IDUs)

$\alpha=$ reduction in frequency of drug injections per day from the cohort data

$\beta=\operatorname{Pr}$ of transmission

$\gamma=$ reported using sterile injection equipment or condom or methadone

$\mathrm{n}=$ number of days follow up

$\mathrm{p}=$ HIV prevalence among IDUs

It was assumed that IDUs inject needles and syringes 400 times per year $[10,41]$ and that they inject constantly for the entire program period. The HIV prevalence rate of IDUs for each intervention were calculated using parameters from different papers $[10,19,25]$, assuming that they are already getting each intervention as data was not available for HIV prevalence rate. The values of alpha and gamma are shown as a proportion, and corresponding parameter values are presented in Table 2.

\section{Distribution of parameters}

To implement Monte Carlo simulation, the costs of each intervention were estimated based on gamma distribution, which is nonnegative and allows the maximum likelihood estimate of the population mean to be the sample mean (Table 2) [42]. The probability distribution of each intervention was estimated with beta distribution, the value of which is between 0 and 1 . Normal distribution was used for utilities of outcome for interventions. For the discount rate, a uniform distribution between 0 and 1 was used. 


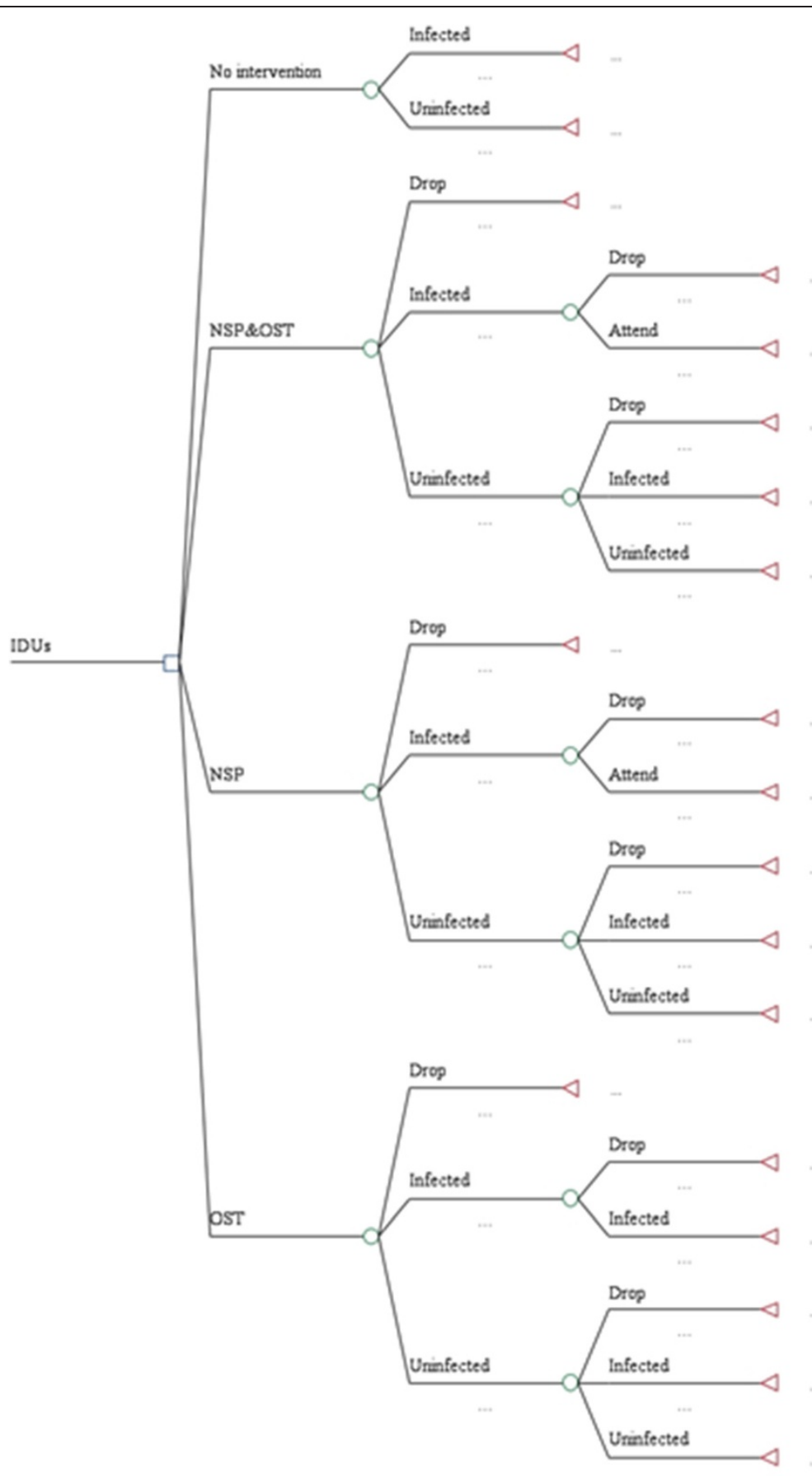

Figure 1 Decision model.

\section{Probability}

In this study, transition probabilities for the 'infected', 'uninfected (well)', and 'dropped' state are shown in Table 2. QALYs for each state were obtained from existing research $[12,25]$.

Cycle times of 1 month or 1 year are generally used in Markov model for chronic diseases [43]. Although 1 year can be used for HIV [44], IDUs can drop out of the interventions sooner. Therefore, a cycle length of 1 month is more appropriate for this model. Since each cycle in the model is 1 month, these transition probabilities were adjusted for a monthly base.

The prevalence rates of each intervention were obtained from previous research that calculated the rates considering needle sharing between IDUs, condom use and sexual behaviours [25]. The dropout rates at each 
Table 2 Model parameters

\begin{tabular}{|c|c|c|c|c|}
\hline \multicolumn{5}{|l|}{ Simulation parameters } \\
\hline HIV incidence & Base case value & Duration & Distribution & Source \\
\hline Number of injections & 400.00 & 1 year & & Degenhardt et al. [10] Aceijas et al. [3] \\
\hline $\begin{array}{l}\text { reduction in frequency of drug injections per } \\
\text { day from the cohort data }\end{array}$ & 0.85 & 1 year & & Alistar, Owens, and Brandeau [19] \\
\hline Pr of transmission & 0.01 & 1 year & & Gouws et al. [30] \\
\hline $\begin{array}{l}\text { using sterile injection equipment or condom } \\
\text { or methadone }\end{array}$ & 0.90 & 1 year & & $\begin{array}{l}\text { Assumed based on Cao et al. [31]; Vickerman } \\
\text { et al. [25]; Alistar et al. [19] }\end{array}$ \\
\hline number of days follow up & 60 cycle(5 years) & $\begin{array}{l}60 \text { months } \\
\text { (treatment) }\end{array}$ & & Global Fund [7] \\
\hline HIV prevalence among IDUs(NSP) & 0.43 & 1 year & & Calculated using Vickerman et al. [25] \\
\hline HIV prevalence among IDUs(OST) & 0.28 & 1 year & & $\begin{array}{l}\text { Calculated using Vickerman et al. [25]; Alistar, } \\
\text { Owens, and Brandeau [19] }\end{array}$ \\
\hline HIV prevalence among IDUs(NSP\&OST) & 0.18 & 1 year & & Calculated using Degenhardt et al. [10] \\
\hline Decrease in HIV incidence(NSP) & 0.22 & 1 year & & Vickerman et al. [25] \\
\hline Decrease in HIV incidence (OST) & 0.53 & 1 year & & Alistar, Owens, and Brandeau [19] \\
\hline Decrease in HIV incidence (NSP\&OST) & 0.66 & 1 year & & Degenhardt et al. [10] \\
\hline \multicolumn{5}{|l|}{ Probability } \\
\hline Pr(attend to intervention) & 0.0750 & 1 cycle & Beta & Assumed \\
\hline $\operatorname{Pr}($ mortality) if no intervention & 0.03 & 1 cycle & Beta & Vickerman et al. [25] \\
\hline Pr(infected) if no intervention & 0.0446 & 1 cycle & Beta & Vickerman et al. [25] \\
\hline $\operatorname{Pr}($ well) if no intervention & 0.0388 & 1 cycle & Beta & calculated \\
\hline Pr(drop) from NSP\&OST & 0.0083 & 1 cycle & Beta & Calculated Pr(attend to intervention) \\
\hline Pr(infected) from NSP\&OST & 0.0003 & 1 cycle & Beta & Degenhardt et al. [10] \\
\hline $\operatorname{Pr}($ well) from NSP\&OST & 0.9914 & 1 cycle & Beta & Calculated \\
\hline $\operatorname{Pr}($ drop) from NSP & 0.0083 & 1 cycle & Beta & Calculated Pr(attend to intervention) \\
\hline $\operatorname{Pr}$ (infected) from NSP & 0.0005 & 1 cycle & Beta & Vickerman et al. [25] \\
\hline $\operatorname{Pr}($ well) from NSP & 0.9912 & 1 cycle & Beta & Calculated \\
\hline $\operatorname{Pr}(d r o p)$ from OST & 0.0083 & 1 cycle & Beta & Calculated Pr(attend to intervention) \\
\hline $\operatorname{Pr}$ (infected) from OST & 0.0004 & 1 cycle & Beta & Alistar, Owens, and Brandeau[19] \\
\hline $\operatorname{Pr}($ well) from OST & 0.9913 & 1 cycle & Beta & Calculated \\
\hline $\operatorname{Pr}(i n f e c t e d)$ if dropped from intervention & 0.0446 & 1 cycle & Beta & Vickerman et al. [25] \\
\hline $\operatorname{Pr}($ well) if dropped from intervention & 0.9554 & 1 cycle & Beta & Calculated \\
\hline $\operatorname{Pr}($ drop) if infected from NSP\&OST & 0.0102 & 1 cycle & Beta & Yin et al. [32]; Jones et al. [11] \\
\hline $\operatorname{Pr}($ attend) if infected from NSP\&OST & 0.9898 & 1 cycle & Beta & Calculated \\
\hline $\operatorname{Pr}($ drop) if infected from NSP & 0.0196 & 1 cycle & Beta & Jones et al. [11] \\
\hline $\operatorname{Pr}($ attend) if infected from NSP & 0.9804 & 1 cycle & Beta & Calculated \\
\hline $\operatorname{Pr}($ drop) if infected from OST & 0.0433 & 1 cycle & Beta & Yin et al. [32] \\
\hline $\operatorname{Pr}($ well) if infected from OST & 0.9567 & 1 cycle & Beta & Calculated \\
\hline \multicolumn{5}{|l|}{ QOL } \\
\hline NSP & 0.85 & & Normal & Vickerman et al. [33] \\
\hline OST & $\begin{array}{l}0.74 \text { (average value } \\
\text { for } 54 \text { week) }\end{array}$ & & Normal & Connock et al. [12] \\
\hline NSP \& OST & 0.95 & & Normal & Vickerman et al. [33] \\
\hline Infected(dropped) & 0.63 & & Normal & Connock et al. [12] \\
\hline
\end{tabular}


Table 2 Model parameters (Continued)

\begin{tabular}{|c|c|c|c|c|}
\hline \multicolumn{5}{|l|}{ Cost } \\
\hline \multicolumn{5}{|l|}{ NSP } \\
\hline unit cost per patient & 151.14 & 1 year & gamma & Global Fund [7] \\
\hline Fixed & 1197008.80 & 1 year & gamma & Estimated from the Global Fund grant proposal \\
\hline \multicolumn{5}{|l|}{ OST } \\
\hline unit cost per patient & 1752.00 & 1 year & gamma & WHO medical database \\
\hline Fixed & 700050.60 & 1 year & gamma & Estimated from the Global Fund grant proposal \\
\hline \multicolumn{5}{|l|}{ NSP\&OST } \\
\hline unit cost per patient(per year) & 1903.14 & 1 year & gamma & Global Fund [7], WHO medical database \\
\hline Fixed & 168286.96 & 1 year & gamma & Assumed from the Global Fund grant proposal \\
\hline \multicolumn{5}{|l|}{ Other parameters } \\
\hline Consumer price index(CPI) & 1.5680 & & & WorldBank [34] \\
\hline Time horizon & 5 years & & & WHO [35] \\
\hline Discount rate for cost & 0.03 & & Uniform & WHO [35] \\
\hline Discount rate for outcome & 0.03 & & Uniform & WHO [35] \\
\hline Population(NSP) & 11000.00 & & & Global Fund [7] \\
\hline Population(OST) & 5000.00 & & & Global Fund [7] \\
\hline Population(NSP \& OST) & 6000.00 & & & Global Fund [7] \\
\hline Initial HIV prevalence among IDUs & 0.53 & 1 year & & Vickerman et al. [25] \\
\hline IDU mortality rate per 1000 person-years & 0.4 & 1 year & & Vickerman et al. [25] \\
\hline
\end{tabular}
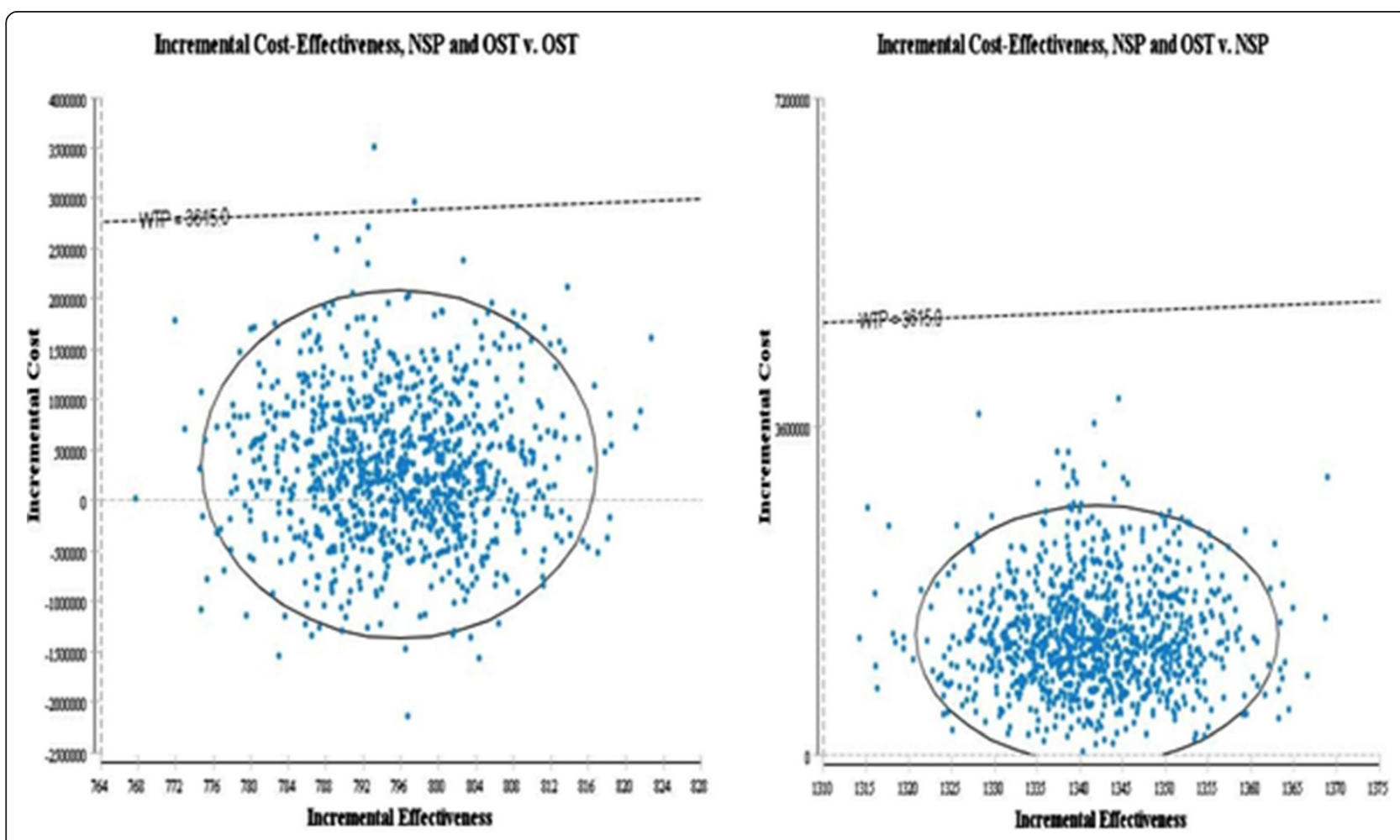

Figure 2 Probabilistic sensitivity analysis(Y axis: Incremental cost X axis: HIV infection averted, Dotted line: WTP = GDP per capita of the Ukraine). 

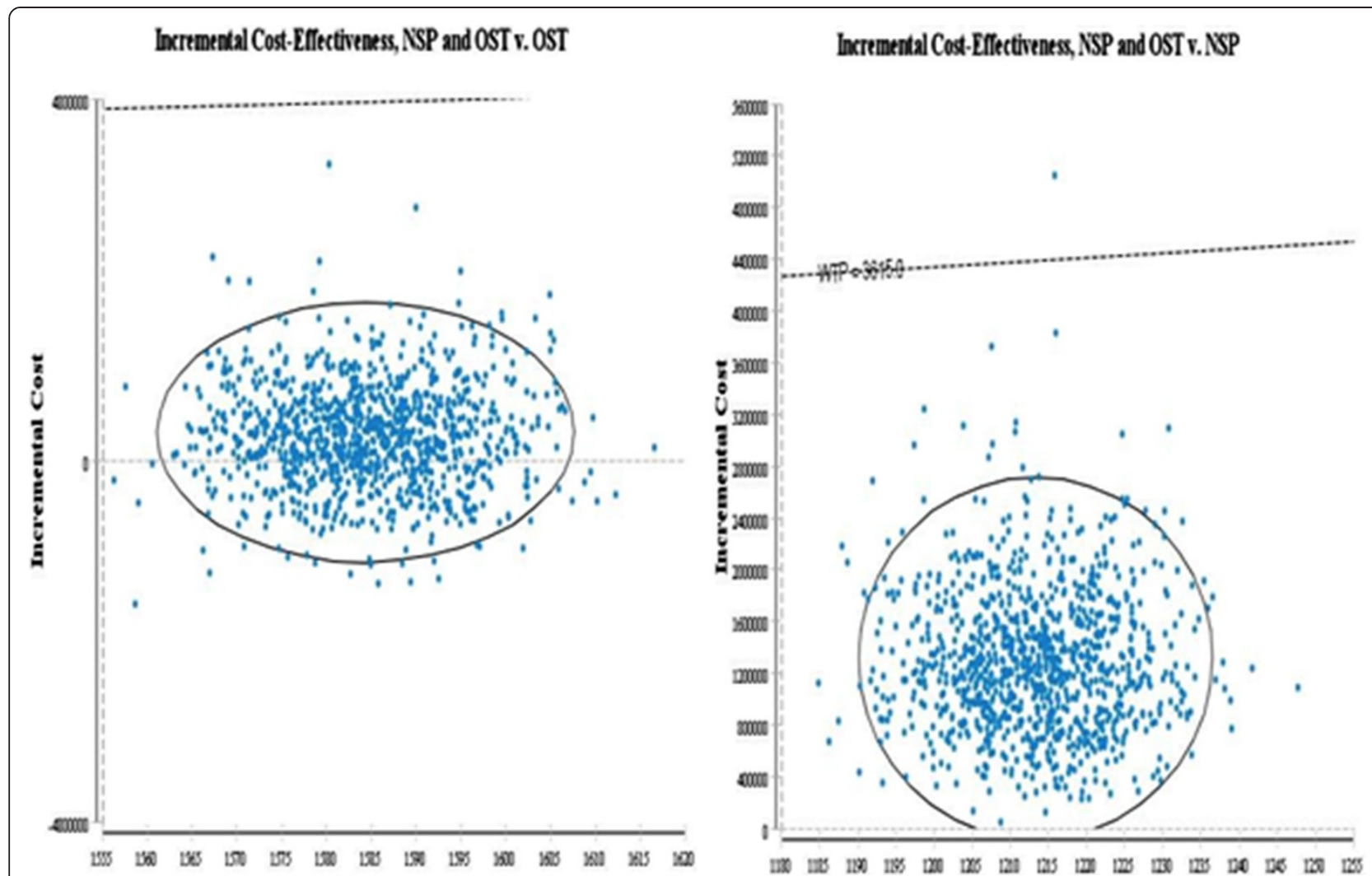

Figure 3 Probabilistic sensitivity analysis(Y axis: Incremental cost X axis: QALYs, Dotted line WTP = GDP of the Ukraine).

cycle, for each intervention, were obtained from existing research [11,32] (Table 2).

\section{Costs}

Cost data were collected from the Global Fund website (www.theglobalfund.org). The Global Fund's intervention in the Ukraine includes various harm-reduction packages [28]. In addition, other interventions were carried out simultaneously including public health education campaigns around harm reduction for IDUs, and other complementary activities. As a result, the exact proportion allocated to the combined intervention is not clear. For the purposes of this analysis then, it was conservatively assumed that the variable cost of the combined strategy is simply the sum of the variable costs for NSP and OST. Alistar et al. [19] calculated the cost of combined intervention of OST and ART in this way. They assumed identical staff costs such as counselling costs for both interventions and that the costs of the combined intervention are the sum of the variable costs for OST and ART. Staff costs and other delivery costs were included in start-up costs for each cycle. The variable costs of each intervention were annualised. Indirect costs, such as productivity loss, were not taken into account in this study and noted as a limitation of this analysis. Budgets for Round 6 (2006-2010) were also used for the combined intervention, although OST alone and the combined intervention was simultaneously implemented. This limitation in the cost data will be tested with sensitivity analysis.

The summarized grant data for the Ukraine is presented in Table 3-a. Costs per cycle were estimated based on the summarized data in Table 3-b, which describe how the harm reduction interventions of NSP and OST were conducted for 5 years. The variable cost of NSP for each cycle in the Ukraine comprises disposable syringes, needles, disinfectant solutions, and alcohol wipes [7]. The variable cost of OST is from the WHO medical database, using the price from Pharmascience.inc [7].

Costs were incurred in United States dollars (USD) and adjusted for inflation to 2011 values using the consumer price index (CPI) for the Ukraine from the World Bank [45]. All costs other than the variable costs of NSP and OST were classified as start-up costs (Table 3-b), which are generated at each Markov cycle of 1 month irrespective of the number of patients. The information regarding the total number of patients to calculate a cost per patient was obtained from the Global Fund website [46] and is presented in Table 2.

\section{Discounting, perspective and time horizon}

The intervention's benefits were evaluated over the duration of the grant period i.e. from the start of 2002 to 
Table 3 Cost data

\begin{tabular}{|c|c|c|c|c|c|c|c|}
\hline \multicolumn{8}{|c|}{ a) Grant data Summary } \\
\hline & Intervention & Year 1 & Year 2 & Year 3 & Year 4 & Year 5 & Total \\
\hline \multirow[t]{2}{*}{ Ukraine } & harm reduction_syringe & 522,600 & $1,372,411$ & $1,901,061$ & $1,900,411$ & $1,951,061$ & $7,647,544$ \\
\hline & Substitution therapy & $1,127,125$ & $1,443,544$ & $3,099,845$ & $3,194,531$ & $3,395,208$ & $12,260,253$ \\
\hline \multicolumn{8}{|c|}{ b) Cost per cycle } \\
\hline \multicolumn{2}{|c|}{ Cost per 1 cycle } & \multicolumn{2}{|l|}{ NSP } & \multicolumn{2}{|l|}{ OST } & \multicolumn{2}{|l|}{ Combined } \\
\hline \multicolumn{2}{|c|}{ Starting up cost } & \multicolumn{2}{|l|}{99750.73} & \multicolumn{2}{|l|}{58337.55} & \multicolumn{2}{|l|}{14023.91} \\
\hline \multicolumn{2}{|c|}{ Cost per patient } & \multicolumn{2}{|l|}{2.52} & \multicolumn{2}{|l|}{29.20} & \multicolumn{2}{|l|}{31.72} \\
\hline \multicolumn{8}{|c|}{ Total cost per 1 cycle } \\
\hline \multicolumn{2}{|c|}{ Cost per patient } & \multicolumn{2}{|l|}{11.59} & \multicolumn{2}{|l|}{40.87} & \multicolumn{2}{|l|}{34.06} \\
\hline
\end{tabular}

*All figures in table 3 is USD.

the end of 2006. Annualized costs were used for each year. As the World Health Organisation (WHO) recommended, an identical discount rate of $3 \%$ was applied to both costs and effectiveness. A provider perspective was applied.

\section{Population}

Using data from the literature, it was assumed that half of IDUs attending the interventions were infected at the outset $[1,25]$ (Table 2) and the average age was assumed to be 39 [47].

\section{Results}

The results of the Markov Monte Carlo simulation are given with $95 \%$ confidence intervals in Table 4 . The result of costs and effectiveness of deterministic analysis is located within the confidence interval of probabilistic analysis, showing the robustness of the result regarding the parameters for this model.

Combined therapy of NSP and OST averted the most infections (1848 HIV infections averted). After this, OST alone averted the most infections (1053 HIV infections averted). Combined therapy averted more infections than the sum of OST alone and NSP alone (1848 HIV infection averted vs 1559 HIV infection averted). Considering QALY gains, combined therapy still gained most (4183.5 QALYs). After this, NSP alone gained slightly more QALYs than OST alone (2970 QALYs vs 2599 QALYs).

Although combined therapy strictly dominated in terms of benefits, NSP alone was most cost effective at \$487.4/ infection averted and \$83.3/QALY gained compared with combined therapy of NSP and OST together at \$851.6/ infection averted and \$373.7/QALYs (Table 4). OST alone had the highest cost effectiveness ratios at $\$ 1145.9$ / infection averted and \$459.9/QALYs.

\section{Sensitivity analysis}

The costs of combined NSP and OST are uncertain due to the limitations of the cost data, which do not explicitly state the total costs of the combined intervention. Consequently, one-way sensitivity analysis was conducted to relax this limitation. The uncertainty of both effectiveness and costs was examined using PSA. The three strategies were compared with a single therapy in Table 5.

Irrespective of the variation in the starting costs of combined intervention, the results are consistent at both outcome measures. It was found that the variation in the start up costs of combined intervention did not affect the rank of strategies in terms of ICER. Although the ICER of combined intervention varies between $\$ 428$ and $\$ 461 /$ infection averted, the rank of ICER for each intervention did not change. Similarly, when presented in QALYs, the ICER of each intervention did not change regardless of the variation in starting up costs.

On the other hand, it was found that the variable cost of OST can affect the relative rank of strategies. At the lower end of OST, OST was most cost effective strategy at both QALYs and infection averted. The ICER of combined intervention [\$428-\$461/infection averted] was slightly lower than the ICER of NSP [\$487/infection averted] although NSP alone is more cost effective. This results from the fact that OST has 'extended dominance' in terms of HIV infections averted and so combined intervention was compared with OST instead of NSP.

In brief, this result relaxes the uncertainty in the start up cost of combined intervention, and offers supporting evidence that the combined intervention and NSP alone are preferred strategies to OST alone. Also, the high variable cost of OST makes OST alone, a less cost effective strategy.

\section{Probability sensitivity analysis}

Figures 2 and 3 shows the results of probabilistic sensitivity analysis with 95\% confidence interval using MonteCarlo simulation.

The result of combined intervention vs NSP alone is located in the first quadrant, suggesting that the combined intervention is incrementally cost effective compared with 
Table 4 10,000 times Monte Carlo simulation results and a deterministic result of cost and effectiveness

\begin{tabular}{|c|c|c|c|c|c|c|c|}
\hline \multirow[t]{2}{*}{ Infection averted } & & \multicolumn{3}{|c|}{ Monte Carlo Simulation } & \multicolumn{3}{|c|}{ Deterministic } \\
\hline & & Combined & NSP & OST & Combined & NSP & OST \\
\hline \multirow[t]{4}{*}{ Cost } & & $1,574,559.00$ & $247,108.68$ & $1,206,760.80$ & $1,565,967.17$ & $247,148.20$ & $1,199,134.00$ \\
\hline & Std & $580,415.89$ & $67,045.82$ & $419,480.75$ & & & \\
\hline & Upper Cl(95\%) & $1,585,935.20$ & $248,422.78$ & $1,214,982.60$ & & & \\
\hline & Lower Cl(95\%) & $1,563,182.90$ & $245,794.58$ & $1,198,539.00$ & & & \\
\hline \multirow[t]{4}{*}{ Effect } & & $1,848.76$ & 506.98 & $1,053.10$ & $1,848.74$ & 506.98 & $1,053.03$ \\
\hline & Std & 6.78 & 5.33 & 5.39 & & & \\
\hline & Upper Cl(95\%) & $1,848.89$ & 507.08 & $1,053.21$ & & & \\
\hline & Lower Cl(95\%) & $1,848.63$ & 506.88 & $1,052.99$ & & & \\
\hline \multirow[t]{4}{*}{ CE } & & 851.68 & 487.41 & $1,145.91$ & 847.05 & 487.49 & $1,138.75$ \\
\hline & Std & 95.06 & 54.01 & 128.57 & & & \\
\hline & Upper Cl(95\%) & 853.55 & 488.47 & $1,148.43$ & & & \\
\hline & Lower Cl(95\%) & 849.82 & 486.35 & $1,143.39$ & & & \\
\hline \multicolumn{8}{|l|}{ QALY } \\
\hline & & combined & NSP & OST & combined & NSP & OST \\
\hline \multirow[t]{4}{*}{ Cost } & & $1,563,571.10$ & $247,577.10$ & $1,195,319.80$ & $1,565,967.17$ & $247,148.20$ & $1,199,134.00$ \\
\hline & Std & $579,705.31$ & $66,864.85$ & $418,960.03$ & & & \\
\hline & Upper Cl(95\%) & $1,574,933.30$ & $248,887.65$ & $1,203,531.40$ & & & \\
\hline & Lower Cl(95\%) & $1,552,208.90$ & $246,266.55$ & $1,187,108.10$ & & & \\
\hline \multirow[t]{4}{*}{ Effect } & & $4,183.51$ & $2,970.21$ & $2,599.08$ & $4,183.51$ & $2,970.21$ & $2,599.04$ \\
\hline & Std & 7.47 & 5.69 & 5.71 & & & \\
\hline & Upper Cl(95\%) & $4,183.66$ & $2,970.32$ & $2,599.19$ & & & \\
\hline & Lower Cl(95\%) & $4,183.36$ & $2,970.10$ & $2,598.97$ & & & \\
\hline \multirow[t]{4}{*}{ CE } & & 373.75 & 83.35 & 459.90 & 374.32 & 83.21 & 461.38 \\
\hline & Std & 95.06 & 54.01 & 128.57 & & & \\
\hline & Upper Cl (95\%) & 374.57 & 83.55 & 460.93 & & & \\
\hline & Lower Cl (95\%) & 372.92 & 83.15 & 458.87 & & & \\
\hline
\end{tabular}

NSP alone. However, the results indicate that the combined intervention may in fact cost less than OST as a single therapy and therefore be the dominant strategy when compared with OST: $31 \%$ of results are in the fourth (south east) quadrant. This means that the probability that the combined intervention is more effective at higher cost, in terms of infection averted, than OST alone is 69\% (first quadrant).

Irrespective of the outcome measures, the combined intervention is located below the line of willingness to pay (WTP) for the Ukraine.

\section{Conclusion}

In this paper, an updated systematic review of the costeffectiveness of harm reduction highlighted a gap in existing evidence: the lack of an incremental approach to comparing the cost effectiveness of combined versus mono-therapy. To fill the evidence gap, this study has attempted to determine the cost-effectiveness of harm reduction by the Global Fund in the Ukraine. A Markov Monte Carlo Model was used to conduct $\mathrm{n}$ incremental economic analysis comparing 3 harm-reduction interventions with one another and with no intervention; i.e. NSP alone, OST alone and combined OST and NSP.

The analysis found that all interventions were cost effective in terms of QALYs gained and HIV infections averted. NSP alone was the most cost effective and OST alone was the least cost effective option. While combined therapy did not have the lowest cost effectiveness ratio, it was significantly more effective in both outcome measures than any alternative. The relatively high variable cost of OST (\$31.72 per patient per cycle) explains, to a large extent, why the combined strategy is not as cost effective as NSP alone.

The result that NSP is most cost-effective, is consistent with previous research on harm-reduction $[19,25]$. NSP alone (\$83.35/QALY in Table 4) is shown to be more cost-effective in the Ukraine than in Australia 
Table 5 Sensitivity analysis

\begin{tabular}{|c|c|c|c|c|c|c|c|c|}
\hline Averted & & Lower end & ICER & $\mathrm{Cl}(95 \%)$ & Higher End & ICER & $\mathrm{Cl}(95 \%)$ & Comparator \\
\hline Variable_NSP & No intervention & 0.00 & 0.00 & & 2.52 & 0.00 & & \\
\hline Variable_NSP & NSP & 0.00 & 296.71 & $293.40: 298.60$ & 2.52 & 487.49 & 484.89:490.09 & vs no intervention \\
\hline Variable_NSP & OST & 0.00 & 1920.53 & 1911.68:1929.38 & 2.52 & 1743.40 & $1734.55: 1752.25$ & vs NSP \\
\hline Variable_NSP & NSP and OST & 0.00 & 461.01 & 452.98:469.04 & 2.52 & 461.01 & 452.98:469.04 & vs OST \\
\hline Variable_OST & No intervention & 0.00 & 0.00 & & 29.20 & 0.00 & & \\
\hline Variable_OST & OST & 0.00 & 83.17 & $82.73: 83.61$ & 29.20 & 1743.40 & $1734.55: 1752.25$ & vs NSP \\
\hline Variable_OST & NSP & 0.00 & -292.22 & $(-294.6):(-289.4)$ & 29.20 & 487.49 & 484.89:490.09 & vs no intervention \\
\hline Variable_OST & NSP and OST & 0.00 & 1857.95 & & 29.20 & 461.01 & 452.98:469.04 & vs OST \\
\hline Startingcost_NSP & No intervention & 0.00 & 0.00 & & 99750.75 & 0.00 & & \\
\hline Startingcost_NSP & NSP & 0.00 & 190.78 & 187.4:192.6 & 99750.75 & 487.49 & 484.89:490.09 & vs no intervention \\
\hline Startingcost_NSP & OST & 0.00 & 2018.89 & 2009.95:2027.65 & 99750.75 & 1743.40 & $1734.55: 1752.25$ & vs NSP \\
\hline Startingcost_NSP & NSP and OST & 0.00 & 461.01 & 452.98:469.04 & 99750.75 & 461.01 & 452.98:469.04 & vs OST \\
\hline Startingcost_combined & No intervention & 0.00 & 0.00 & & 14023.92 & 0.00 & & \\
\hline Startingcost_combined & NSP & 0.00 & 487.49 & 484.89:490.09 & 14023.92 & 487.49 & 484.89:490.09 & vs no intervention \\
\hline Startingcost_combined & OST & 0.00 & 1743.40 & $1734.55: 1752.25$ & 14023.92 & 1743.40 & 1734.55:1752.25 & vs NSP \\
\hline Startingcost_combined & NSP and OST & 0.00 & 428.49 & 419.96:436.03 & 14023.92 & 461.01 & 452.98:469.04 & vs OST \\
\hline Startingcost_OST & No intervention & 0.00 & 0.00 & & 58337.53 & 0.00 & & \\
\hline Startingcost_OST & NSP & 0.00 & 487.49 & 484.89:490.09 & 58337.53 & 487.49 & 484.89:490.09 & vs no intervention \\
\hline Startingcost_OST & OST & 0.00 & 1583.01 & 1574.15:1591.85 & 58337.53 & 1743.40 & $1734.55: 1752.25$ & vs NSP \\
\hline Startingcost_OST & NSP and OST & 0.00 & 571.08 & $562.97: 579.03$ & 58337.53 & 461.01 & 452.98:469.04 & vs OST \\
\hline \multicolumn{9}{|l|}{ QALYs } \\
\hline Variable_NSP & No intervention & 0.00 & 0.00 & & 2.52 & 0.00 & & \\
\hline Variable_NSP & NSP & 0.00 & 50.65 & $50.2: 51.08$ & 2.52 & 83.21 & $82.76: 83.65$ & vs no intervention \\
\hline Variable_NSP & OST & 0.00 & -2825.37 & $\begin{array}{l}(-2836.71): \\
(-2793.29)\end{array}$ & 2.52 & -2564.79 & $\begin{array}{l}(-2585.71): \\
(-2542.29)\end{array}$ & vs NSP \\
\hline Variable_NSP & NSP and OST & 0.00 & 1166.69 & 1150.94:1181.07 & 2.52 & 1086.97 & 1077.76:1096.24 & vs NSP \\
\hline Variable_OST & No intervention & 0.00 & 0.00 & & 29.20 & 0.00 & & \\
\hline Variable_OST & OST & 0.00 & 33.70 & $30.63: 36.75$ & 29.20 & 83.21 & 79.94:86.06 & vs no intervention \\
\hline Variable_OST & NSP & 0.00 & 429.90 & 419.96:436.03 & 29.20 & -2564.79 & $\begin{array}{l}\text { (-2585.71): } \\
(-2542.29)\end{array}$ & vs OST \\
\hline Variable_OST & NSP and OST & 0.00 & 1086.97 & 1077.76:1096.24 & 29.20 & 1086.97 & 1077.76:1096.24 & vs NSP \\
\hline Startingcost_combined & No intervention & 0.00 & 0.00 & & 14023.92 & 0.00 & & \\
\hline Startingcost_combined & NSP & 0.00 & 83.21 & $82.76: 83.65$ & 14023.92 & 83.21 & $82.76: 83.65$ & vs no intervention \\
\hline Startingcost_combined & OST & 0.00 & -2564.79 & $\begin{array}{l}(-2585.71): \\
(-2542.29)\end{array}$ & 14023.92 & -2564.79 & $\begin{array}{l}(-2585.71): \\
(-2542.29)\end{array}$ & vs NSP \\
\hline Startingcost_combined & NSP and OST & 0.00 & 1065.64 & 1049.93:1080.07 & 14023.92 & 1086.97 & 1077.76:1096.24 & vs NSP \\
\hline Startingcost_NSP & No intervention & 0.00 & 0.00 & & 99750.75 & 0.00 & & \\
\hline Startingcost_NSP & NSP & 0.00 & 32.56 & 29.49:35.62 & 99750.75 & 83.21 & $82.76: 83.65$ & vs no intervention \\
\hline Startingcost_NSP & OST & 0.00 & -2970.06 & $\begin{array}{l}\text { (-2991.71): } \\
(-2948.29)\end{array}$ & 99750.75 & -2564.79 & $\begin{array}{l}\text { (-2585.71): } \\
(-2542.29)\end{array}$ & vs NSP \\
\hline Startingcost_NSP & NSP and OST & 0.00 & 1210.95 & 1194.93:1225.06 & 99750.75 & 1086.97 & 1077.76:1096.24 & vs NSP \\
\hline Startingcost_OST & No intervention & 0.00 & 0.00 & & 58337.53 & 0.00 & & \\
\hline Startingcost_OST & NSP & 0.00 & 83.21 & $82.76: 83.65$ & 58337.53 & 83.21 & $82.76: 83.65$ & vs no intervention \\
\hline Startingcost_OST & OST & 0.00 & -2328.83 & $\begin{array}{l}(-2350.54): \\
(-2307.12)\end{array}$ & 58337.53 & -2564.79 & $\begin{array}{l}(-2585.71): \\
(-2542.29)\end{array}$ & vs NSP \\
\hline Startingcost_OST & NSP and OST & 0.00 & 1086.97 & 1077.76:1096.24 & 58337.53 & 1086.97 & 1077.76:1096.24 & vs NSP \\
\hline
\end{tabular}


[\$416-8,750/QALY] [22] or Kazakhstan [\$132-147/ QALY] [48], However, the cost effectiveness ratio of NSP alone in this study, at $\$ 487.41$ per HIV infection averted, is significantly higher than that from another study in the Ukraine study [\$97-162 per HIV infection averted] [25]. OST, at $\$ 459.90$ per QALY, was slightly more cost-effective than other analyses for the Ukraine suggest [\$530/QALY] [19]. Regardless, OST was a dominated strategy for both outcome measures and this is attributed to the high variable cost of OST. The results of the sensitivity analysis support this conclusion.

From the result of PSA, the samples are located below the slope of willingness to pay (WTP). Considering that the GDP of the Ukraine was $\$ 3,615$ in 2011 [34], all three interventions were found to be located below the cost effectiveness threshold suggested by the WHO [35]. As a result, and given the significant dominance of combined therapy in terms of benefits, this is may be the preferred strategy in the Ukraine context. That said, a discussion about affordability and the ethics of selecting a less effective strategy may be warranted in this context.

Some caveats exist in this study and the generalizability of the findings, which should be noted. Firstly, the start-up costs of combined intervention are uncertain. This makes it more important to measure uncertainty and sensitivity in costs. Also, the probability of transmission used in this study assumes normal IDUs. However, depending on the IDUs' status (i.e. sex workers or men who have sex with men (MSM)), the probability will vary. Likewise, the assumption that the variable cost of the combined strategy is simply the sum of the variable costs for NSP and OST can be relaxed with more detailed information regarding cost data. Another caution is that the effectiveness parameters, such as dropout rates, will vary depending on how an intervention is implemented in practice. Therefore, the 'dominance' of each strategy over comparators should be carefully interpreted. Also, the GDP threshold is a weak indicator of affordability and more work is needed in this area.

More detail on the number of IDUs reached by Global Fund NSP and OST programs would further improve the accuracy of estimates. With more evidence regarding the effectiveness of harm reduction programs, including those supported by the Global Fund, greater support for effective - and cost effective - harm reduction can be fostered.

\section{Abbreviation \\ NSP: Needle and syringe programme; OST: Opioid substitution therapy; ART: Anti-retroviral therapy; IDUs: Injecting drug users.}

\section{Competing interest}

The authors declare that they have no competing interests.

\section{Authors' contribution}

SWK carried out the economic evaluation, and drafted the manuscript. AMP and JSW participated in study design and coordination and helped to draft the manuscript. All authors read and approved the final manuscript.

\section{Author details}

${ }^{1}$ UCL Institute for Global Health, 30 Guilford Street, London WC1N 1EH, UK. 2Epidemiology and Global Health Department, Umeå University, Umea, Sweden. ${ }^{3}$ London School of Hygiene and Tropical Medicine, Keppel Street, London, WC1E 7HT, UK.

Received: 16 June 2014 Accepted: 17 November 2014

Published: 24 November 2014

\section{References}

1. IHRA: The global state of harm reduction 2012: towards an intergrated response. London Int Harm Reduct Assoc 2012, Available from: http://www.ihra.net/global-state-of-harm-reduction-2012.

2. Atun $R$, Kazatchkine M: The Global Fund's leadership on harm reduction: 2002-2009. Int J Drug Policy 2010, 21(2):103-106. Available from: http://www.ncbi.nlm.nih.gov/pubmed/20171865.

3. Aceijas C, Hickman M, Donoghoe MC, Burrows D, Stuikyte R: Access and coverage of needle and syringe programmes (NSP) in Central and Eastern Europe and Central Asia. Addiction 2007, 102(8):1244-1250. Available from: http://www.ncbi.nlm.nih.gov/pubmed/17565564.

4. UNAIDS: Injecting Drug use: Focused HIV Prevention Works. 2007.

5. UNAIDS: World AIDS DAY report 2012-Regional fact sheet. 2012. Available from: http://www.unaids.org/en/resources/campaigns/20121120_ globalreport2012/factsheet/.

6. Nieburg P, Carty L: Injection Drug Use in Ukraine: The Challenges of Providing HIV Prevention and Care, A report of the CSIS Global Health Policy Center. Washington, DC: Center for Strategic \& International Studies; 2012:1.

7. GlobalFund: Proposal form_SIXTH CALL FOR PROPOSALS. 2006. Available from: http://www.theglobalfund.org/en/.

8. Matic S, Lazarus J, Donoghoe M: HIV/AIDS in Europe. WHO regional office for Europe; 2006.

9. Drucker $E$, Lurie $P$, Wodak $A$, Alcabes $P$ : Measuring harm reduction: the effects of needle and syringe exchange programs and methadone maintenance on the ecology of HIV. AIDS 1998, 12(Suppl A):S217-S230. Available from: http://www.ncbi.nlm.nih.gov/pubmed/9633006.

10. Degenhardt L, Mathers B, Vickerman P, Rhodes T, Latkin C, Hickman M: Prevention of HIV infection for people who inject drugs: why individual, structural, and combination approaches are needed. Lancet 2010, 376(9737):285-301. Available from: http://www.ncbi.nlm.nih.gov/pubmed/ 20650522

11. Jones L, Pickering L, Sumnall H, Mcveigh J, Mark A, Bellis M: A Review of the Effectiveness and Cost-Effectiveness of Needle and Syringe Programmes for Injecting Drug Users Final Full Report (Revised). 2008. NICE.orgUK.

12. Connock M, Juarez-Garcia A, Jowett S, S; Frew E, Liu Z, Taylor RJ, Fry-Smith A, Day E, Lintzeris N, Roberts T, Burls A, Taylor RS: Methadone and buprenorphine for the management of opioid dependence: a systematic review and economic evaluation. Health Technol Assess (Rockv) 2007, 11(9). Available from: http://www.ncbi.nlm.nih.gov/pubmed/17313907.

13. Belani HK, Muennig PA: Cost-effectiveness of needle and syringe exchange for the prevention of HIV in New york city. J HIV AIDS Soc SerV 2008, 7(3):229-240. Available from: http://www.tandfonline.com/doi/abs/ 10.1080/15381500802307492.

14. Wammes JJG, Siregar AY, Hidayat T, Raya RP, van Crevel R, van der Ven AJ, Baltussen R: Cost-effectiveness of methadone maintenance therapy as HIV prevention in an Indonesian high-prevalence setting: a mathematical modeling study. Int J Drug Policy 2012, 23(5):358-364. Available from: http://www.ncbi.nlm.nih.gov/pubmed/22884538.

15. Guinness L, Vickerman P, Quayyum Z, Foss A, Watts C, Rodericks A, Azim T, Jana S, Kumaranayake L: The cost-effectiveness of consistent and early intervention of harm reduction for injecting drug users in Bangladesh. Addiction 2010, 105(2):319-328. Available from: http://www.ncbi.nlm.nih. gov/pubmed/19922513.

16. Tran BX, Mills S, Houston S, Jacobs P: Cost-effectiveness of methadone maintenance treatment for HIV-positive drug users in Vietnam. AIDS Care Psychol Socio-Medical Asp AIDS/HIV 2013, 2012:37-41.

17. Tran BX, Nguyen T, Vu PX, Mills S, Houston S, Jacobs P: The costeffectiveness and budget impact of Vietnam's methadone maintenance treatment programme in HIV prevention and treatment among injection drug users. Glob Public Heal An Int J Res Policy Pract 2012, 7(10):1080-1094.

18. Tran BX, Ohinmaa A, Duong AT, Nguyen LT, Vu PX, Mills S, Houston S, Jacobs P: Cost-effectiveness of integrating methadone maintenance and 
antiretroviral treatment for HIV-positive drug users in Vietnam's injection-driven HIV epidemics. Drug Alcohol Depend 2012, 125(3):260-266. Available from: http://www.ncbi.nlm.nih.gov/pubmed/22436971.

19. Alistar SS, Owens DK, Brandeau ML: Effectiveness and cost effectiveness of expanding harm reduction and antiretroviral therapy in a mixed HIV epidemic: a modeling analysis for Ukraine. PLoS Med 2011, 8(3):e1000423. Available from: http://www.pubmedcentral.nih.gov/articlerender.fcgi? artid $=3046988 \&$ tool $=$ pmcentrez\&rendertype $=$ abstract

20. Li J, Gilmour S, Zhang H, Koyanagi A, Shibuya K: The epidemiological impact and cost-effectiveness of HIV testing, antiretroviral treatment and harm reduction programs. AIDS 2012, 26(16):2069-2078. Available from: http://www.ncbi.nlm.nih.gov/pubmed/22781221.

21. Van Den Berg C, Smit C, Van Brussel G, Coutinho R, Prins M: Full participation in harm reduction programmes is associated with decreased risk for human immunodeficiency virus and hepatitis $C$ virus: evidence from the Amsterdam Cohort Studies among drug users. Addiction 2007, 102(9):1454-1462. Available from: http://www. pubmedcentral.nih.gov/articlerender.fcgi?artid=2040242\&tool=pmcentrez\& rendertype $=$ abstract

22. Kwon JA, Anderson J, Kerr CC, Thein H-H, Zhang L, Iversen J, Jenny D, Gregory JK, John ML, Matthew GM, Lisa W, David P: Estimating the cost-effectiveness of needle-syringe programs in Australia. AIDS 2012, 26(17):2201-10. Available from: http://www.ncbi.nlm.nih.gov/pubmed/ 22914579

23. Zhang $L$, Yap $L$, Xun Z, Wu Z, Wilson DP: Needle and syringe programs in Yunnan, China yield health and financial return. BMC Public Health [Internet]. BioMed Central 2011, 11(1):250. Available from: http://www. pubmedcentral.nih.gov/articlerender.fcgi?artid=3102626\&tool=pmcentrez\& rendertype $=$ abstract.

24. Tran BX, Ohinmaa A, Duong AT, Do NT, Nguyen LT, Nguyen QC, Tran BX Ohinmaa A, Duong AT, Do NT, Nguyen LT, Nguyen QC, Mills S, Jacobs P, Houston S: Changes in drug use are associated with health-related quality of life improvements among methadone maintenance patients with HIV/ AIDS. Qual Life Res 2012, 21(4):613-623. Available from: http://www.ncbi.nlm. nih.gov/pubmed/21732198.

25. Vickerman P, Kumaranayake L, Balakireva O, Guinness L, Artyukh O, Semikop T, Yaremenko $\mathrm{O}$, Watts $\mathrm{C}$ : The cost-effectiveness of expanding harm reduction activities for injecting drug users in Odessa, Ukraine. Sex Transm Dis 2006 33(10 Suppl):S89-S102. Available from: http://www.ncbi.nlm.nih.gov/pubmed/ 16735956.

26. Aceijas C, Oppenheimer E, Stimson GV, Ashcroft RE, Matic S, Hickman M: Antiretroviral treatment for injecting drug users in developing and transitional countries 1 year before the end of the "Treating 3 million by 2005. Making it happen. The WHO strategy" ("3 by 5"). Addiction 2006, 101(9):1246-1253. Available from: http://www.ncbi.n/m.nih.gov/pubmed/ 16911723

27. Wolfe D, Carrieri MP, Shepard D: Treatment and care for injecting drug users with HIV infection: a review of barriers and ways forward. Lance 2010, 376(9738):355-366. Available from: http://www.ncbi.nlm.nih.gov/ pubmed/20650513.

28. Bridge J, Hunter BM, Atun R, Lazarus JV: Global Fund investments in harm reduction from 2002 to 2009. Int J Drug Policy 2012, 23(4):279-285. Available from: http://www.ncbi.nlm.nih.gov/pubmed/22421551

29. Barnett PG: The cost effectiveness of methadone maintenance as a health care intervention. Addiction 1999, 94(4):479-488.

30. Gouws E, White PJ, Stover J, Brown T: Short term estimates of adult HIV incidence by mode of transmission: Kenya and Thailand as examples. Sex Transm Infect 2006, 82(Suppl 3):iii51-iii55. Available from: http://www. pubmedcentral.nih.gov/articlerender.fcgi?artid=2576735\&tool=pmcentrez\& rendertype=abstract.

31. Cao W, Treloar C: Comparison of needle and syringe programme attendees and non-attendees from a high drug-using area in Sydney, New South Wales. Drug Alcohol Rev 2006, 25(5):439-444.

32. Yin W, Hao Y, Sun X, Gong X, Li F, Li J, Yin W, Hao Y, Sun X, Gong X, Li F, Li J, Rou K, Sullivan SG: Scaling up the national methadone maintenance treatment program in China: achievements and challenges. Int J Epidemiol 2010, 39(Suppl 2):ii29-ii37.

33. Vickerman P, Miners A, Williams J: Assessing the cost-effectiveness of interventions linked to needle and syringe programmes for injecting drug users: An economic modelling report Authors. 2008:1-89. NICE.orgUK

34. WorldBank: GDP per capita. 2013.
35. WHO: Cost-effectiveness thresholds [Internet]. 2013. Available from: http:// www.who.int/choice/costs/CER_thresholds/en/.

36. Winston WL: "How Many Trials Do We Need?" in the book Simulation Modeling Using @RISK. Duxbury: Cengage Learning; 2000.

37. Supervie V, García-Lerma JG, Heneine W, Blower S: HIV, transmitted drug resistance, and the paradox of preexposure prophylaxis. Proc Natl Acad Sci U S A 2010, 107(27):12381-12386.

38. Wilson DP, Coplan PM, Wainberg MA, Blower SM: The paradoxical effects of using antiretroviral-based microbicides to control HIV epidemics. Proc Natl Acad Sci U S A 2008, 105(28):9835-9840.

39. Sonnenberg FA, Beck JR: Markov Models in Medical Decision Making: A Practical Guide. Med Decis Mak 1993, 13(4):322-338.

40. Zulliger R, Black S, Holtgrave DR, Ciaranello AL, Bekker L-G, Myer L: Cost-effectiveness of a package of interventions for expedited antiretroviral therapy initiation during pregnancy in Cape Town, South Africa. AIDS Behav 2014, 18(4):697-705. Available from: http://www.ncbi.nlm.nih.gov/ pubmed/24122044.

41. Aceijas C, Stimson GV, Hickman M, Rhodes T: Global overview of injecting drug use and HIV infection among injecting drug users on behalf of the United Nations Reference Group on HIV/AIDS Prevention and Care among IDU in Developing and Transitional. 2004.

42. Briggs A, Nixon R, Dixon S, Thompson S: Parametric modelling of cost data: some simulation evidence. Health Econ 2005, 14(4):421-428.

43. Price MJ, Briggs AH: Development of an Economic Model to Assess the Cost Effectiveness of Asthma Management Strategies. Pharmacoeconomics 2002, 20(3):183-194.

44. Drummond M, Sculpher M, Torrance G, O'Brien BJ, Stoddart G: Methods for the Economic Evaluation of Health Care Programmes. Oxford University Press; 2005.

45. WorldBank: Consumer price index [Internet]. 2014. Available from: http://data worldbank.org/indicator/FP.CPI.TOTL.

46. The global Fund [Internet]. Available from: www.theglobalfund.org

47. Bruce RD, Dvoryak S, Sylla L, Altice FL: HIV treatment access and scale-up for delivery of opiate substitution therapy with buprenorphine for IDUs in Ukraine-programme description and policy implications. Int I Drug Policy 2007, 18(4):326-328. Available from: http://www.pubmedcentral.nih. gov/articlerender.fcgi?artid=2084072\&tool=pmcentrez\&rendertype=abstract.

48. Wilson DP, Zhang L, Kerr C, Kwon A: Evaluating the cost-effectiveness of needle-syringe exchange programs in Kazakhstan Period of 2000-2010 2011 Report. 2011:1-35.

doi:10.1186/1478-7547-12-25

Cite this article as: Kim et al.: Comparing the cost effectiveness of harm reduction strategies: a case study of the Ukraine. Cost Effectiveness and Resource Allocation 2014 12:25.

\section{Submit your next manuscript to BioMed Central and take full advantage of:}

- Convenient online submission

- Thorough peer review

- No space constraints or color figure charges

- Immediate publication on acceptance

- Inclusion in PubMed, CAS, Scopus and Google Scholar

- Research which is freely available for redistribution 